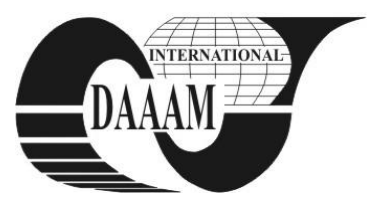

Annals of DAAAM for 2012 \& Proceedings of the 23rd International DAAAM Symposium, Volume 23, No.1, ISSN 2304-1382 ISBN 978-3-901509-91-9, CDROM version, Ed. B. Katalinic, Published by DAAAM International, Vienna, Austria, EU, 2012 Make Harmony between Technology and Nature, and Your Mind will Fly Free as a Bird Annals \& Proceedings of DAAAM International 2012

\title{
DETERMINATION OF DIESEL ENGINES REGULATING CHARACTERISTICS
}

\author{
GRUESCU, C[onstantin] A[ndrei]; VELA, I[on] \& CARAMIDARU, V[irgil] D[an]
}

\begin{abstract}
The calculus of the control or adjustment system for supercharged Diesel engines supposes determining the adjustment characteristics for all the devices composing the system. Such a device is the system of levers between governor and engine meant to transmit the governor movement to the fuel-injection pumps rack of the engine according to a linear relationship. In this paper the authors present the calculation algorithm and computer software developed for a certain application which is used for numerical simulating on computer of the levers system operation in the adjustment range. Thus one may determine the adjustment characteristic of this mechanism. The methodology is applicable for any type of engine and is useful for engine designers, manufacturers and beneficiaries.
\end{abstract}

Keywords: diesel engine, adjustment characteristics, locomotives, ships

\section{INTRODUCTION}

In the automatic control system of the Diesel engines for all the applications, we encounter a lever mechanism, with a specific structure for each type of engine, which connects the governor to the engine fuel injection system. In the case of traction engines for locomotives or ships, the control system has mainly the role to ensure the engine operation on the optimal propulsion characteristic - power depending on speed. This objective is achieved through adoption of a suitable governor characteristic travel depending on speed as in [1] and of an adequate characteristic and proper adjustment for the system of levers [2].

The engine control system maintains a constant speed (number of revolutions) for each speed step commanded by the mechanic (notch) by varying the fuel rack position which controls the debit of fuel injected per cycle into the engine. Between the governor travel $(\mathrm{T})$ and the speed (n) there is a well defined relationship of a degree similar to the relation between the rack travel (R) and engine speed (n') and thus between the governor travel and the fuel rack travel a linear relationship of variation must be achieved as in [2], so that between the engine power and the fuel rack travel one could assume a relation directly proportional of variation [3]. The reaching of this relation must be achieved by the lever systems. Due to the interdependency between the parameters ( $T$ and $R$ ), it is obvious that one must grant a special attention to the design and adjustment on the engine (in manufacture or operation) of the system of levers, as long as this is where one fulfils the correlation of the values of certain important parameters intervening in the calculus of the characteristics of the control systems [2].
Any deviation of parameters values from those admitted in calculus, as a result of an improper or poorly adjusted system of levers, leads to an inadequate functioning of the engine [2], [4], [5]. Thus, a correctly conceived adjustment system may be compromised during manufacturing or service, as a result of insufficient knowledge of the influence of the levers adjustment system on the system.

The defect is difficult to identify in the absence of an appropriate calculation, which should simulate the operation of this mechanism within the chosen adjustment range.

\section{NUMERICAL SIMULATION OF THE FUEL LINKAGE}

The authors propose an analytical method to solve such a mechanism [6], [7], providing, in this respect, the calculation algorithm and the computer simulation software, for a real application presented in Fig.1.

The purpose followed through fuel linkage simulation

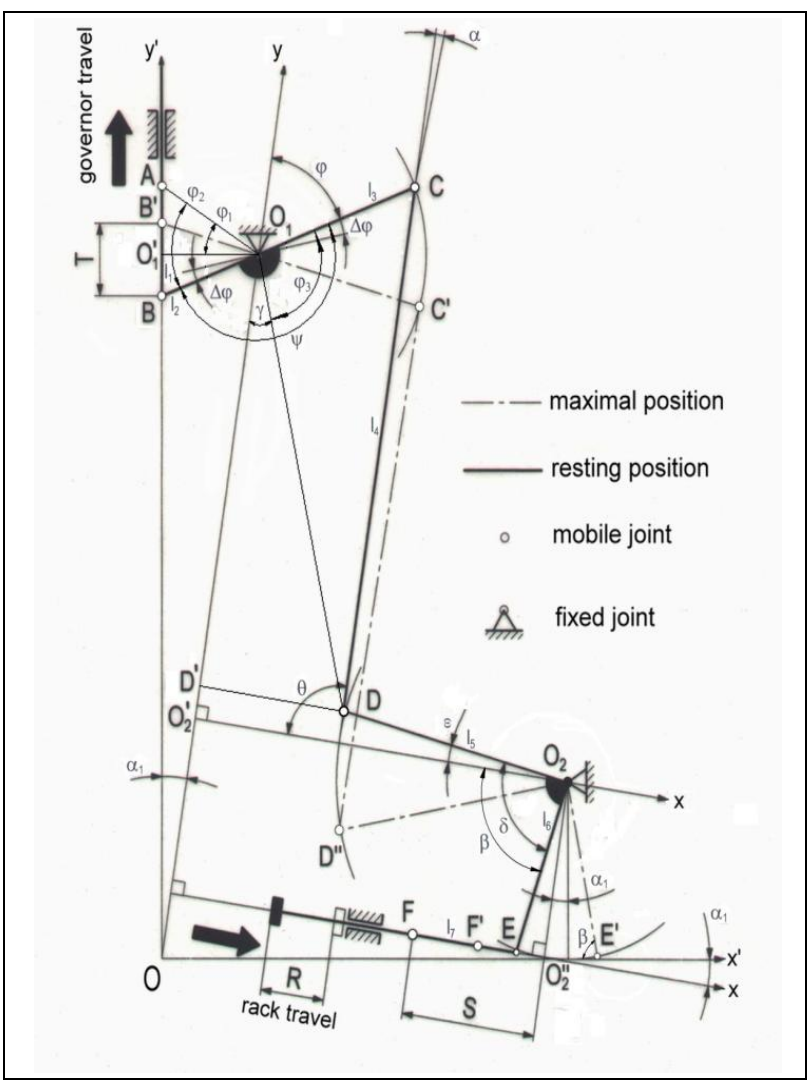

Fig. 1. Schematic of the levers system 
is determination of the regulating characteristic of this system $\mathrm{R}=\mathrm{f}(\mathrm{T})$ - rack depending on governor travel useful for designing engineer in the correlation process of the main regulating parameters and at the control system optimizing.

The mechanism in Fig.1: has seven levers of different lengths in its structure $\left(1_{1} \ldots 1_{7}\right),\left(\mathrm{AB}=\mathrm{l}_{1} ; \mathrm{BO}_{1}=\mathrm{l}_{2} ; \mathrm{O}_{1} \mathrm{C}=\mathrm{l}_{3}\right.$; $\left.\mathrm{CD}=\mathrm{l}_{4} ; \quad \mathrm{DO}_{2}=\mathrm{l}_{5} ; \quad \mathrm{O}_{2} \mathrm{E}=\mathrm{l}_{6} ; \quad \mathrm{EF}=\mathrm{l}_{7}\right)$ among which two adjustable levers $\left(1_{3}, l_{4}\right)$ : is coupled with the governor in joint $(\mathrm{A})$ and with fuel rack in joint $(\mathrm{F})$; the co-ordinates of fixed joints $\left(\mathrm{O}_{1}, \mathrm{O}_{2}\right)$, the initial co-ordinates of mobile joints $(\mathrm{A}, \mathrm{F})$ and lengths of all levers are known; the boundary conditions are known. In Fig. 1 the mechanism is plotted in resting position and in the maximum running position.

Resting position of the mechanism from Fig.1, characterized through "zero" travel of the fuel injection pumps rack corresponding to "zero" governor travel, is defined by the angles: $\beta, \varepsilon, \gamma, \varphi$ and $\psi$, which are calculated with the following formulas:

$$
\beta=\arccos \frac{S-\ell_{7}}{\ell_{6}} ;
$$

from $\Delta \mathrm{O}_{2} \mathrm{EO}_{2}$ ", where $\mathrm{S}=53[\mathrm{~mm}]$

$$
\begin{gathered}
\varepsilon=\delta-\beta ; \\
\gamma=\operatorname{arctg} \frac{\ell_{x}-\ell_{5} \cdot \cos \varepsilon}{\ell_{y}-\ell_{5} \cdot \sin \varepsilon} ;
\end{gathered}
$$

from $\Delta \mathrm{O}_{1} \mathrm{DD}$

$$
\begin{gathered}
O_{1} D=\frac{\ell_{x}-\ell_{5} \cdot \cos \varepsilon}{\sin \gamma} ; \\
\varphi_{3}=\arccos \frac{\ell_{3}^{2}+O_{1} D^{2}-\ell_{4}^{2}}{2 \cdot \ell_{3} \cdot O_{1} D} ; \\
\varphi=180^{\circ}-\left(\varphi_{3}+\gamma\right) ; \\
\varphi_{1}=\operatorname{arctg} \frac{y_{A}^{\prime}}{x_{A}^{\prime}} ;
\end{gathered}
$$

from $\Delta \mathrm{AO}_{1} \mathrm{O}_{1}$

$$
\varphi_{2}=\arccos \frac{\ell_{2}^{2}+A O_{1}^{2}-\ell_{1}^{2}}{2 \cdot \ell_{2} \cdot A O_{1}} ;
$$

from $\Delta \mathrm{AO}_{1} \mathrm{~B}$

$$
\begin{gathered}
A O_{1}=\sqrt{x_{A}{ }^{\prime 2}+y_{A}{ }^{\prime 2}} ; \\
\psi=90^{\circ}-\left(\varphi_{2}-\varphi_{1}\right)-\alpha_{1}+\gamma+\varphi_{3} .
\end{gathered}
$$

For the analytical solving of the mechanism, useful in the simulating process, one considers the vector outline $\left(\mathrm{O}_{1} \mathrm{CDO}_{2} \mathrm{O}_{2}{ }^{\prime}\right)$ and the system of co-ordinates axes $\left(\mathrm{xO}_{2}{ }^{\prime} \mathrm{y}\right)$. By projecting the outline on the co-ordinates axes we obtain:

$$
\left\{\begin{array}{l}
\ell_{x}=\ell_{3} \cdot \sin (\varphi+\Delta \varphi)-\ell_{4} \cdot \sin \alpha+\ell_{5} \cdot \cos \varepsilon \\
\ell_{y}=-\ell_{3} \cdot \cos (\varphi+\Delta \varphi)+\ell_{4} \cdot \cos \alpha+\ell_{5} \cdot \sin \varepsilon
\end{array} ;\right.
$$

where: $1_{\mathrm{x}}=\mathrm{O}_{2} \mathrm{O}_{2}{ }^{\prime} ; 1_{\mathrm{y}}=\mathrm{O}_{1} \mathrm{O}_{2}{ }^{\prime}$. We eliminate the angle $\varepsilon$ from (11) by raising to square power and addition and then by substituting:

$$
\begin{gathered}
a=\ell_{y}+\ell_{3} \cdot \cos (\varphi+\Delta \varphi) ; \\
b=\ell_{x}-\ell_{3} \cdot \sin (\varphi+\Delta \varphi) ; \\
c=\frac{a^{2}+b^{2}+\ell_{4}{ }^{2}-\ell_{5}{ }^{2}}{2 \cdot a \cdot \ell_{4}} ; \\
d=\frac{b}{a} ;
\end{gathered}
$$

we obtain:

$$
\cos \alpha-d \cdot \sin \alpha=0 .
$$

Substituting in (12) $\sin \alpha$ by $\cos \alpha\left(\sin ^{2} \alpha=1-\cos ^{2} \alpha\right)$ after raising to square power we obtain (13) with the solutions (14):

$$
\begin{aligned}
& \cos ^{2} \alpha \cdot\left(d^{2}+1\right)-2 \cdot c \cdot \cos \alpha-d^{2}+c^{2}=0 ; \\
& \alpha_{1,2}=\arccos \frac{c \pm \sqrt{c^{2}-\left(d^{2}+1\right) \cdot\left(c^{2}-d^{2}\right)}}{d^{2}+1} .
\end{aligned}
$$

One selects the smaller value of the angle $\alpha$. Knowing the initial value of the angle $\varphi$ calculated for the resting position of the mechanism from Fig.1 with (6) and $\Delta \varphi$ angle, calculated with (15) for each position of the mechanism within the adjustment range, in conveniently chosen steps, we may determine the co-ordinates of joint point $\mathrm{C}\left(\mathrm{x}_{\mathrm{c}}, \mathrm{y}_{\mathrm{c}}\right)$ :

$$
\Delta \varphi=2 \cdot \arcsin \frac{T}{2 \cdot \ell_{2}} ;
$$

where: $\mathrm{T}$ is the governor travel

$$
\left\{\begin{array}{l}
x_{C}=\ell_{3} \cdot \sin (\varphi+\Delta \varphi) \\
y_{C}=\ell_{y}+\ell_{3} \cdot \cos (\varphi+\Delta \varphi)
\end{array} .\right.
$$

The straight line (17) passing through joint (C) with the tilt $\left(\theta=90^{\circ}-\alpha\right)$ will be intersected by the circle (18) with the centre in $\mathrm{O}_{2}\left(\mathrm{x}_{\mathrm{O} 2}, \mathrm{y}_{\mathrm{O} 2}=0\right)$ and with radius $1_{5}$ :

$$
\begin{aligned}
& y_{D}-y_{C}=m \cdot\left(x_{D}-x_{C}\right) ; \\
& \left(x_{O_{2}}-x_{D}\right)^{2}+y_{D}{ }^{2}=\ell_{5}{ }^{2} ;
\end{aligned}
$$

where: $\mathrm{m}=\operatorname{tg} \theta ; \mathrm{x}_{\mathrm{O} 2}=\mathrm{l}_{\mathrm{x}}$.

From this intersection one obtains (19) of which solutions represents the abscissas for joint point $\mathrm{D}$ $\left(\mathrm{x}_{\mathrm{D}}, \mathrm{x}_{\mathrm{D}}{ }^{\prime}{ }^{\prime}\right)$.

$$
p \cdot x_{D}^{2}-q \cdot x_{D}+r r=0
$$

where:

$$
\left\{\begin{array}{l}
p=1+m^{2} \\
q=2 \cdot\left(m \cdot y_{C}-x_{O_{2}}-m^{2} \cdot x_{C}{ }^{2}\right) \\
r r=x_{O_{2}}{ }^{2}+y_{C}{ }^{2}-\ell_{5}{ }^{2}-2 \cdot m \cdot x_{C} \cdot y_{C}+m^{2} \cdot x_{C}{ }^{2} \\
d d=q^{2}-4 \cdot p \cdot r r
\end{array}\right.
$$

The solutions of (19) will be:

$$
x_{D}{ }^{\prime}=\frac{q+\sqrt{d d}}{2 \cdot p} ; x_{D}{ }^{\prime \prime}=\frac{q-\sqrt{d d}}{2 \cdot p} .
$$


One chooses for $x_{D}$ the smaller value and $y_{D}$ value must meet the condition that the distance between joint points (C) and (D) be equal with length $1_{4}$ :

$$
y_{D}=y_{C}-\sqrt{\ell_{4}^{2}-\left(x_{C}-x_{D}\right)^{2}} .
$$

With (22) one calculates the angle $\varepsilon$ and then one intersects the straight line $\left(\mathrm{O}_{2} \mathrm{E}\right)(23)$, with the tilt $\beta=\delta$ $+\varepsilon$, with the circle (24) of radius $\mathrm{l}_{6}$ and centre $\mathrm{O}_{2}$, from where the abscissas for joint $\mathrm{E}\left(\mathrm{x}_{\mathrm{E} 1}, \mathrm{x}_{\mathrm{E} 2}\right)$ result as solutions of (25):

$$
\begin{aligned}
& \varepsilon=\operatorname{arctg} \frac{y_{O_{2}}-y_{D}}{x_{O_{2}}-x_{D}} ; \quad y_{O_{2}}=0 ; \\
& \left\{\begin{array}{l}
y_{E}=\operatorname{tg} \beta \cdot\left(x_{O_{2}}-x_{E}\right) \\
f o r_{-} \beta \leq 90^{\circ}{ }_{-} \operatorname{tg} \beta=m^{\prime} \\
y_{E}=\operatorname{tg}\left(180^{\circ}-\beta\right) \cdot\left(x_{O_{2}}-x_{E}\right) \\
\text { for_ } \beta>90^{\circ}{ }_{-} \operatorname{tg}\left(180^{\circ}-\beta\right)=m^{\prime}
\end{array}\right. \\
& \left(\begin{array}{l}
\left.x_{E}-x_{O_{2}}\right)^{2}+y_{E}{ }^{2}=\ell_{6}{ }^{2} ; \\
p^{\prime} \cdot x_{E}{ }^{2}-q^{\prime} \cdot x_{E}+r r^{\prime}=0 ;
\end{array}\right.
\end{aligned}
$$$$
\text { where: }\left\{\begin{array}{l}
p^{\prime}=1+m^{\prime 2} \\
q^{\prime}=2 \cdot\left(1+m^{\prime 2}\right) \cdot x_{O_{2}} \\
r r^{\prime}=\left(1+m^{\prime 2}\right) \cdot x_{O_{2}}{ }^{2}-\ell_{6}{ }^{2} \\
d d^{\prime}=q^{\prime 2}-4 \cdot p^{\prime} \cdot r r^{\prime}
\end{array}\right.
$$

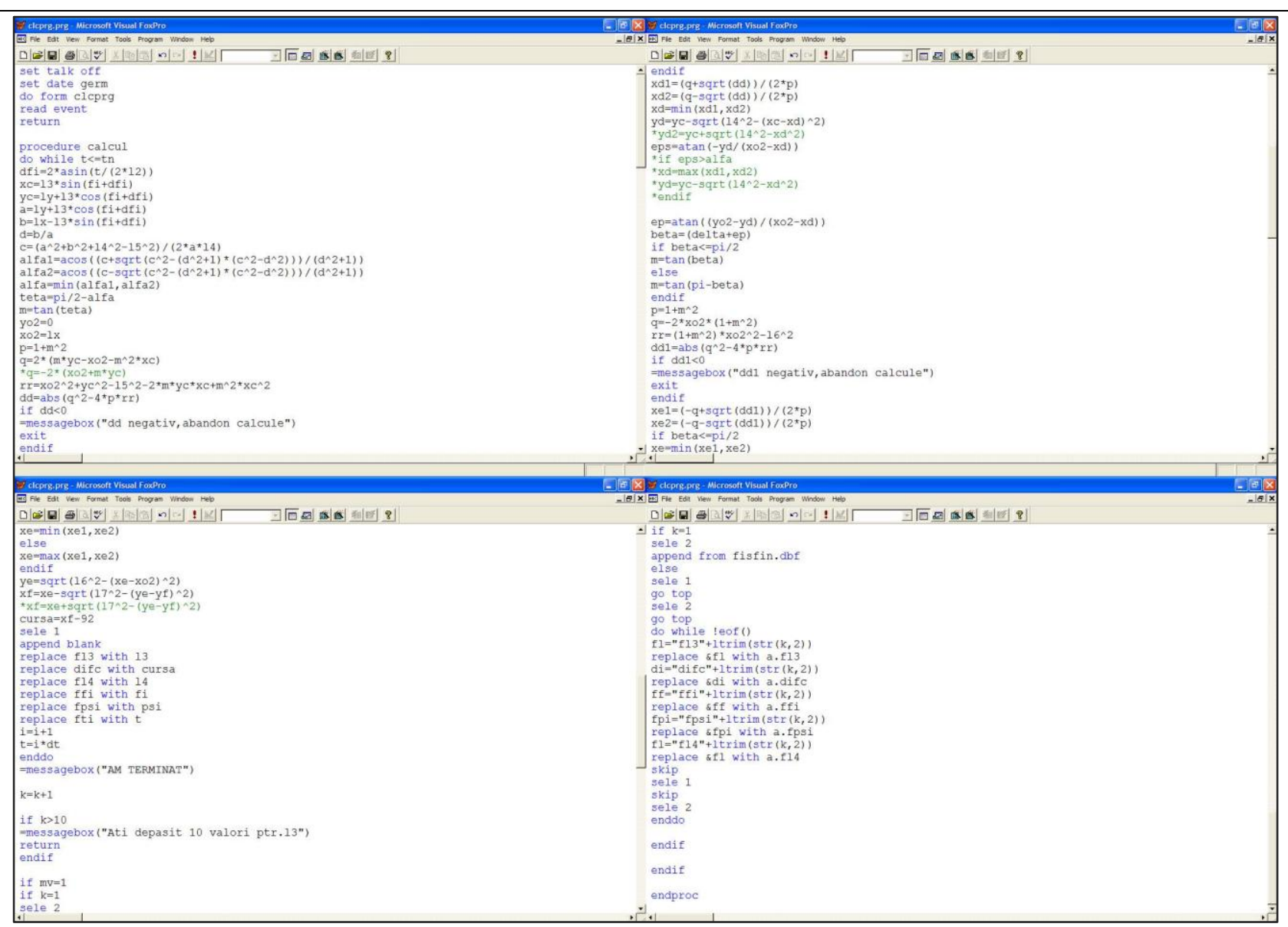

Fig. 2. Simulation software
The solutions of (25) will be:

$$
x_{E_{1}}=\frac{q^{\prime}+\sqrt{d d^{\prime}}}{2 \cdot p^{\prime}} ; x_{E_{2}}=\frac{q^{\prime}-\sqrt{d d^{\prime}}}{2 \cdot p^{\prime}} \text {. }
$$

One selects the smaller value of $x_{E}$ till $\beta=90^{\circ}$ and then the bigger one. With $\mathrm{x}_{\mathrm{E}}$ selected one calculated $\mathrm{y}_{\mathrm{E}}$ with (27):

$$
y_{E}=\sqrt{\ell_{6}^{2}-\left(x_{E}-x_{O_{2}}\right)^{2}} .
$$

From condition than distance between joints (E) and (F) be equal with $1_{7}$ length are determined the abscissa of joint $\mathrm{F}\left(\mathrm{x}_{\mathrm{F}}\right)$; $\mathrm{y}_{\mathrm{F}}=\mathrm{ct}$.:

$$
x_{F}=x_{E}-\sqrt{\ell_{7}^{2}-\left(y_{E}-y_{F}\right)^{2}} .
$$

The difference between abscissas of the joint $(F)$, realised during fuel linkage simulation, from "zero" governor travel through nominal value, and reference abscissa of joint $\mathrm{F}\left(\mathrm{x}_{\mathrm{Fo}}\right)$, represent the rack travels (R) realised:

$$
R=x_{F}-x_{F_{0}}
$$

where: $\quad x_{F_{0}}=x_{O_{2}}-S$ (s. Fig.1).s

\section{DETERMINATION OF LEVERS SYSTEM CHARACTERISTIC}

For numerical simulation of the system of levers was programming language which is presented in Fig.2. conceived a software using Microsoft Visual Fox Pro 
Practically, starting from the initial value of the angle $(\varphi)$ and of the reference abscissa $\left(\mathrm{x}_{\mathrm{Fo}}\right)$, corresponding to the resting position of the levers mechanism, which corresponds to "zero" governor and rack travel, using numerical simulation software presented in Fig.2, is determined the corresponding abscissa of the joint point $\mathrm{F}\left(\mathrm{x}_{\mathrm{F}}\right)$ for values of the governor travel $\mathrm{T}$, in suitable selected steps, from "zero" to maximum value. The steps are expressed through $(\Delta \varphi)$ angle which is calculated with $(15)$, where $(\Delta \mathrm{T})$ is the governor travel step.

Thus, one calculates, for each step, the rack travel performed by the levers mechanism in relation with the governor travel, with the lengths of all levers established at concrete values. Graphically (Fig.3) one plots the characteristic curve - rack travel (R) depending on the governor travel $(\mathrm{T})$ - with the values resulted from the calculus and are compared these values with the similar values adopted at the calculus of the control system and also is verified the shape of the characteristic curve.

If these values are not equal, the correlation of the parameters is not achieved or the shape of the characteristic is not adequate, will be used the correction possibilities of the mechanism i.e. modifying the length of levers $\left(l_{3}\right.$ or $\left.l_{4}\right)$ and the calculation is remade. Thus, are obtained a lot of characteristics, as seen in Fig.3, from which the designing engineer must select the best solution (i.e. optimal characteristic "model" from Fig.3), through which are correlated all the adjusting parameters.

The values of the adjustment parameters that must be correlated are: $R_{n}$ with $T_{n}$ - corresponding to nominal speed and power of the engine; $R_{g}$ with $T_{g}-$ corresponding to idle speed without load; $R_{p \lim =0}$ with $T_{p \lim =0}$ and $R_{0}$. The $T_{p \text { lim }=0}$ value is used for the calculation of the characteristic curve of the governor fuel limiter with (30) deduced by the author in [2]:

$$
p_{\lim }=\frac{\left(T-T_{p . \lim =0}\right)^{2}}{\left(T_{n}-T_{p . \lim =0}\right)^{2}} \cdot p_{n \cdot \lim }
$$

where $\mathrm{T}_{\mathrm{plim}=0}$ represents the governor travel $\mathrm{T}$ at limiting, for "zero" supercharging air pressure of the engine.

The travel of the fuel rack $R_{p \lim }=0$ it is a very important parameter which must be correlated with the governor travel $\mathrm{T}_{\mathrm{p} \text { lim=0 }}$ (s. Fig.3). This parameter is specific for each engine or engines family and it indirectly expresses the maximal injection allowed for a supercharged Diesel engine when supercharging has not started yet $(\mathrm{p}=0)$ or the turbo-charger has broken down.

The rack travel $\mathrm{R}_{0}$, corresponding to zero governor travel, which results in the optimising process of the levers system characteristic $\mathrm{R}=\mathrm{f}(\mathrm{T})$, can not exceed a maximal value imposed by the injection pumps manufacturer because, in certain conditions, the engine over speeding one can produces.

The research described in this paper has applicable character and constitute a real example which can be followed. It leads to improvement of the Diesel engines adjustment and was applied by the author at adjusting system optimizing of the engines family for which was created the solution. The research has no limitations. It can be used as model in the future researches for other applications.

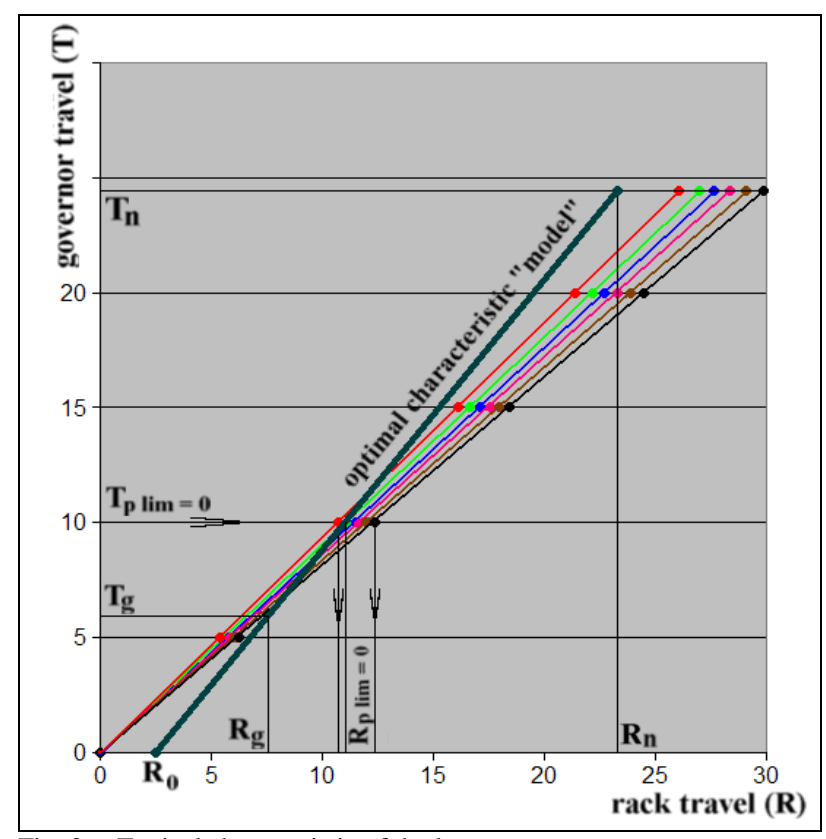

Fig. 3. Typical characteristic of the levers system

\section{CONCLUSIONS}

The functional simulation of the levers system by mathematical calculation allows the determination of the characteristic curve - rack travel depending on governor travel $R=f(T)$ - which is essential for the accurate understanding of the way in which characteristics of the adjustment system are transmitted to the Diesel engine.

Only through this verification can be guaranted the engine running on the optimal propulsion characteristic and thus we can obtain the necessary information for an accurate adjustment of this mechanism.

Using the proposed calculation methodology, the designing engineer can easily obtain any loading variants of the same engines, by merely changing the length of the levers from the mechanism. Moreover, knowing the characteristic curve - rack travel depending on governor travel - is very useful in the process of optimizing the control system and for the analysis and correction of governing troubles triggered by inadequate adjustments of the levers system.

\section{REFERENCES}

[1] Gruescu, C. A., Vela, I., Caramidaru, V. D., (2012). Optimising the Regulating System of Supercharged Diesel Engines, Proceedings of the 8TH International Conference of Daaam Baltic Industrial Engineering, 19-21st April 2012, Tallinn, Estonia, ISBN 978-9949-23-265-9, Editor T.Otto, pp.51-56, DAAAM Baltic Tallinn University of Technology, Tallin

[2] Gruescu, C. A., (2011). Regulating System Calculus for Supercharged Diesel Engines of Variable Speed, "Eftimie Murgu" University of Resita, Report, unpublished

[3] Bowers, R. J., (1988) Control Systems for Diesel Electric Locomotives, Prime Mover Control Conference PMCC-88-2E, Woodward Governor Company.

[4] Woodward Governor Company, Analysis and Correction of PG Governing Troubles, Bulletin 36404B, Ft. Collins, Colorado, USA

[5] Woodward Governor Company, (1984), PGA Governor, Manual 36699, Ft. Collins, Colorado, USA

[6] [6] Kovacs, Fr., (1977), Mechanisms. Synthesis of Mechanisms, I.P.T.V. Timisoara

[7] Popescu, I., (1977), Designing of Plane Mechanisms, Craiova 